\title{
Anatomic connections of the diaphragm: influence of respiration on the body system
}

This article was published in the following Dove Press journal:

Journal of Multidisciplinary Healthcare

24 July 2013

Number of times this article has been viewed

\author{
Bruno Bordoni' \\ Emiliano Zanier ${ }^{2}$ \\ 'Rehabilitation Cardiology Institute \\ of Hospitalization and Care with \\ Scientific Address, S Maria Nascente \\ Don Carlo Gnocchi Foundation, \\ ${ }^{2}$ EdiAcademy, Milano, Italy
}

\begin{abstract}
The article explains the scientific reasons for the diaphragm muscle being an important crossroads for information involving the entire body. The diaphragm muscle extends from the trigeminal system to the pelvic floor, passing from the thoracic diaphragm to the floor of the mouth. Like many structures in the human body, the diaphragm muscle has more than one function, and has links throughout the body, and provides the network necessary for breathing. To assess and treat this muscle effectively, it is necessary to be aware of its anatomic, fascial, and neurologic complexity in the control of breathing. The patient is never a symptom localized, but a system that adapts to a corporeal dysfunction.
\end{abstract}

Keywords: diaphragm, fascia, phrenic nerve, vagus nerve, pelvis

\section{Anatomy and anatomic connections}

The diaphragm is a dome-shaped musculotendinous structure that is very thin $(2-4 \mathrm{~mm})$ and concave on its lower side and separates the chest from the abdomen. ${ }^{1}$ There is a central tendinous portion, ie, the phrenic center, and a peripheral muscular portion originating in the phrenic center itself. ${ }^{2}$ With regard to anatomic attachments, a costal, a lumbar, and a sternal portion can be identified.

The sternal portion, which is made up of two tiny muscle bundles, derives from the back of the xiphoid process near the apex and delimits an irregular opening located in the medial area, ie, Larrey's fissure, through which the prepericardial connective tissue contacts the preperitoneal connective tissue. ${ }^{3} \mathrm{~A}$ logical deduction is that the connection between the chest and the abdomen is an anatomic continuum, where the diaphragm plays a vital role in managing the information related to both cavities. Laterally, there are two interstices (the foramen of Morgagni, where the arteria mammaria interna runs) that are covered by the pleura and the adjacent pericardium; these are worth mentioning because it is via these openings that anteromedial and retrocostoxiphoid hernias can occur. ${ }^{4}$

The costal (lateral) section originates on the internal surface and the superior margin of the last six inferior ribs, via six digitations that intersect those of the transversus abdominis muscle. ${ }^{1,2}$ At times, the costal tracts along with the lumbar tracts outline a triangular interstice known as Bochdalek's triangle (or the lumbocostal triangle), a site of possible hernia. ${ }^{5}$

The lumbar section derives from the medial, intermedial, and lateral diaphragmatic pillars, and it is important to emphasize the fact that the main pillars, ie, the medial and lateral pillars, make contact with the retropericardial and the perinephric tract,
Correspondence: Bruno Bordoni

Rehabilitation Cardiology IRCCS,

S Maria Nascente Don Carlo Gnocchi

Foundation, via Capecelatro 66,

Milano, Italy

Tel +02403081

Fax +02 $34963006 \quad 17$

Email bordonibruno@hotmail.com 
and their related fat. ${ }^{6}$ This is important for two reasons: first, it is a further demonstration of the continuous connection existing between the various body structures, and second, the visceral fat is a source of proprioceptive information from the diaphragm itself, and establishes once more the role played by this organ in affecting structures that are distant from each other. $^{7}$ Before attaching to the vertebral soma, the medial pillars demarcate at the T11 level, with their internal muscular bundles, the opening of the esophagus, where the esophagus and the vagal nerves pass. ${ }^{8}$ The right medial pillar, which is thicker and longer than its lateral counterpart, becomes a flat tendon that ends on the anterior side of L2-L3, and at times, L4. ${ }^{9}$ Beside the right pillar there is a small tract known as the accessory, medial, or intermedial pillar, the tendon of which goes between L1 and L2. ${ }^{9}$ A vertical opening is visible between this pillar and the right medial pillar, where the greater splanchnic nerve and the radix medialis of the azygos vein run, and the diaphragm is crossed also by smaller and minimum splanchnic nerves. ${ }^{10,11}$ The left medial pillar terminates as a flat tendon between L2 and L $3,{ }^{9}$ and again an accessory pillar is traceable, which outlines an opening for the greater splanchnic nerve and the radix medialis of the hemiazygos vein. ${ }^{10,11}$ Their tendons are shaped as a tendinous arc in front of T12 (median arcuate ligament), and is crossed by the aortic artery and thoracic duct. ${ }^{8,12}$ The lateral pillars insert here and split into two robust tendons: one, the medial arcuate ligament (above the psoas muscle) bridging the L1 vertebra and the transverse apophysis, ${ }^{13}$ and the other, the lateral arcuate ligament (above the quadratus lumborum muscle) connecting the transverse process of L1 and the apex of the twelfth rib. ${ }^{14}$ The medial and lateral arcuate ligaments act as a bridge between the thoracolumbar fascia posteriorly and the transversalis fascia anteriorly. ${ }^{15-17}$ In the phrenic center, the vena cava passes through an opening, located anteriorly on the right (Figure 1). ${ }^{8}$

This brief description demonstrates how the diaphragm is both an important exchange point of information, originating in different areas of the body, and a source of information in itself.

The superior diaphragmatic surface merges into the pulmonary pleura, whereas the inferior surface merges into the peritoneum. ${ }^{16,18,19}$

The diaphragm is permeated by collaterals of the arteria mammaria interna, collaterals of the abdominal aorta, and other vessels originating from intercostal arteries. ${ }^{9}$ The veins are the continuation of the arteries, and drain into the musculophrenic veins and into the inferior diaphragmatic veins. ${ }^{9}$ The diaphragmatic ligaments are structures

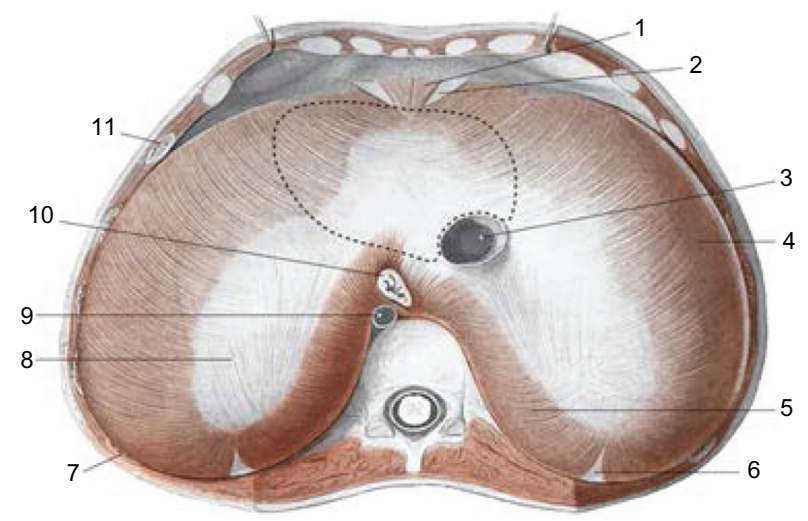

Figure I The area above the diaphragm: the dotted line for the support of heart 3: inferior vena cava; 10: esophagus; 9: aorta; 8: tendinous center; 5: lumbar area. AA VV, Anatomia dell'uomo, 4 ed, Edi.ermes, Milano [Several authors, Human Anatomy, Fourth Edition, edition EdiErmes]. www.eenet.it.

that connect the diaphragm to the viscera. The inferior pulmonary ligament is a pleural thickening connecting the diaphragm to the base of the lungs, ${ }^{20}$ the phrenopericardial ligament connects the diaphragm to the heart; ${ }^{9}$ the phrenicoesophageal ligament joins the esophagus and the diaphragm and is composed of loose connective tissue; ${ }^{21}$ the hepatic ligaments, ie, the falciform ligament and the right and left triangular ligaments, represent a subdiaphragmatic peritoneal thickening; ${ }^{9}$ the phrenicocolic ligament connects the diaphragm to the angle of the right ascending colon; ${ }^{22}$ and finally, the ligament of Treitz is constituted by a series of muscular tracts that start in the main left pillar and go to the duodenojejunal angle. ${ }^{23,24}$ Also worth mentioning is Glisson's capsule, which is a structure over the liver resulting from separation of the phrenic center of the diaphragm. ${ }^{25}$ The phrenopericardial ligament is the fulcrum around which the diaphragm is supported when it comes to distribute its contractile tension laterally. ${ }^{26}$

From a functional perspective, two areas can be recognized in the diaphragm, ie, the crural region and the costal region. The former is responsible for correct breathing, whereas the latter prevents gastroesophageal reflux. This separation has an anatomic function, because during deglutition, esophageal distention, and vomiting, these diaphragmatic areas must work at different times and with different innervations (Figure 2). ${ }^{27}$

Another matter to consider is the connection between the respiratory and pelvic diaphragms. During normal respiration, or in the event of coughing or any other physiologic diaphragmatic alteration, a symmetric change in the pelvic floor can be observed. ${ }^{28}$ For instance, if during inspiration the main inspiratory muscle descends, there will be a corresponding lowering of the pelvic floor. ${ }^{28}$ This process has 


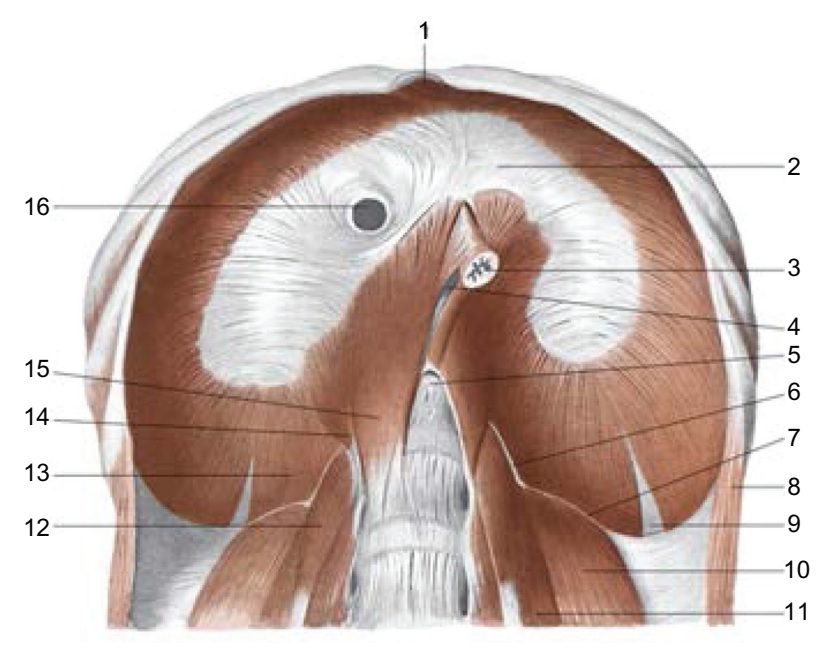

Figure 2 The sub-diaphragmatic area: 2: tendinous center or phrenic; 16: inferior vena cava; 3: esophagus; 5: aortic orifice; 15: medial pillar; 14: intermediate pillar; 13: pillar lateral; 6: pillar arcuate medial; 7: lateral arcuate ligament; 10: quadratus lumborum muscle; II: psoas major muscle.

AA VV, Anatomia dell'uomo, 4 ed, Edi.ermes [Several authors, Human Anatomy, Fourth Edition, edition EdiErmes], Milano. www.eenet.it

been confirmed during real-time magnetic resonance studies in living subjects with the aim of controlling (and responding to) any change in intra-abdominal pressure. ${ }^{28}$ It also ensures the steadiness of the human trunk and maintaining urinary continence during respiration and coughing. ${ }^{28}$ Various studies have established that, before inhalation, electrical activity can be observed in the muscles of the pelvic floor, ${ }^{28}$ and the same electrical activity is traceable for the transverse and obliquus internus abdominis muscles. ${ }^{28}$

The pelvic diaphragm not only has a significant role in supporting the pelvic organs and in resisting increasing pressure, but also affects respiratory function. ${ }^{28}$ The retroambiguus nucleus, which is an important monitoring center for phrenic medullary areas and housed in the medulla oblongata or so-called bulb, also controls the abdominal muscles. ${ }^{29,30}$ This means that respiration needs to be supported by the pelvic floor in order to control the pressure of intra-abdominal fluid properly. It is probable that these same areas, which are connected to the motor neurons of the floor of the mouth, send the premotor impulse to the pelvic zone.

\section{Neurologic connections}

It is important to remember that the embryology of the diaphragm explains these connections further, but is not well understood. ${ }^{3,31}$ The phrenic nerve innervates the diaphragm, and runs from the roots of $\mathrm{C} 3$ to $\mathrm{C} 5 ;^{32}$ the phrenic neurons are housed in lamina IX of the ventral horn in the cervical spinal cord, and receive information via presynaptic contacts in the medulla. ${ }^{33}$ According to some authors, the pathway of the phrenic nerve involves the entire brachial plexus and the entire cervical plexus (C1-T1). ${ }^{34}$

The phrenic motor units not only control breathing but also have other functions that are not specifically breathing actions, such as deglutition, vocalization, and the expulsion of waste-containing substances for the expectoration of the airways. ${ }^{35}$ This set of medullary interneurons, which sends impulses to the phrenic motor neurons, is known as the preBotzinger complex or the parafacial retrotrapezoid nucleus, although the exact system is still disputed. ${ }^{33}$ Studies in animal models speculate that these medullary areas can send autonomous electrical impulses for respiration, independent of the central nervous system. ${ }^{33}$ Recent research suggests that the retroambiguus nucleus controls these medullary areas from the occipital area. ${ }^{33}$ Further, it is possible to influence the diaphragm and cardiac frequency from the occipital bone. ${ }^{36,37}$ Once in the diaphragm, the phrenic nerve splits into numerous branches. ${ }^{38}$ The intercostal nerves have been shown not to send motor information to the diaphragm. ${ }^{38}$ Filaments of the costal nerves are distinguishable amid the arterial vessels that enter the diaphragm, where they may play a vascular proprioceptive role, and in proximity of the connective tissue of the diaphragm muscle, always with a proprioceptive role. ${ }^{38}$ It has been shown recently that the various branches of the phrenic nerve are directly related to the vascular tree that permeates the muscle, so that the nerve itself controls the blood supply of the area concerned during the electrical motor impulse, managing the vasodilation. ${ }^{39}$ It is important to remember that the phrenic nerve receives afferents from the pericardium, liver, vena cava, and peritoneum, since it contains both sensory and motor fibers. ${ }^{9,27,40}$ Recent studies suggest that the crural region of the diaphragm receives sensitive motor efferents from the vagus, ${ }^{41,42}$ which explains why the few neuromuscular spindles in the muscle are found mainly in the crura. ${ }^{27}$ During inhalation, if there is an alimentary bolus, the crural region stops working in order to send the bolus into the stomach. ${ }^{27}$ This probably involves distal inhibition of the phrenic nerve, deriving from crural vagal information. ${ }^{27}$

The brachial and cervical plexuses are located in the region of the phrenic nerve. ${ }^{9}$ To give some examples, the roots that may be affected by phrenic disorders are $\mathrm{C} 4-\mathrm{C} 5$ (ie, the dorsal nerve of the scapula), and C5-C6, specifically, the axillary nerve, suprascapular nerve, musculocutaneous nerve, and subclavian nerve. ${ }^{9}$ The electrical activity of the nervous system is not restricted to the mere distribution of efferent impulses in one direction; in fact, nerves not only convey electrical impulses but also release chemobiologic, neurotrophic and, at times, immune substances. ${ }^{43-45}$ 
This process, which is not simply an electrical activity, can take place both in afferent and efferent mode, regardless of the function of the nerve. ${ }^{46}$ For instance, depending on the nature of the muscular contraction, contractile tissue synthesizes neurotrophic molecules (such as NT3, NT4, and BDNF), which can move along the axis cylinder in a retrograde manner, until reaching the motor neuron, in order to modify its form and, as a result, its function. ${ }^{47,48}$ Therefore, a disorder of the phrenic nerve, even when peripheral, such as a diaphragmatic disorder, transmits chemobiologic and metabolic information to the medullary neurons and interneurons adjacent to the set of phrenic motor neurons, affecting other sensitive motor neurons or neurons at the same level, whether ipsilaterally or contralaterally. ${ }^{4}$

It is easier to transmit an electrical impulse to a precise point rather than send a metabolic message to a single neuron. For this reason, it is possible to verify a symptomatology that is different from a mere breathing disorder, such as brachialgia, ie, pain in the shoulder. ${ }^{49,50}$ Along its pathway, the phrenic nerve anastomoses to the subclavian nerve, which innervates the subclavian muscle, specifically, the first rib and the clavicle (C5-C6) ${ }^{34}$ Therefore, if there is a phrenic disorder, it is possible to contract the subclavius muscle, raising the first rib and reproducing a thoracic outlet syndrome, with the relevant symptomatology; ${ }^{51,52}$ for instance, pressure on $\mathrm{C} 8-\mathrm{T} 1$ can cause problems in the little finger. ${ }^{53}$ The scalene muscles, which are innervated by the cervical and brachial plexuses, are equally important. ${ }^{9}$ It is worth emphasizing that a brachial disorder can provoke phrenic and diaphragmatic disorders. ${ }^{54}$ The same occurs for any other anatomic connection. Moreover, the phrenic nerve meets the stellate ganglion (and indirectly the cardiac ganglion), which is located above the first rib and generated from the unification of the median ganglion and the inferior cervical ganglion, ${ }^{9,55-57}$ meaning that a disorder of the former or latter will produce symptoms throughout the cervical tract. There is a close link between the diaphragm and the thoracic outlet.

With reference to neurology, the phrenic nerve along its pathway anastomoses with the vagus, while the vagus runs through the crural region of the diaphragm, innervating this area. ${ }^{9,27,58}$ It is generally believed that the esophageal afferents of the vagus exert an inhibitory influence on the medullary and phrenic motor neurons ${ }^{27}$ If there is a problem in the diaphragm or phrenic nerve, the whole system that controls the crural region is negatively affected, causing esophageal reflux and/or swallowing problems. ${ }^{39,59,60}$ The vagus is joined to the medial longitudinal fasciculus by afferent and efferent connections; moreover, it is in contact with the spinal trigeminal nucleus via afferent connections. ${ }^{9,58,61,62}$ This means that diaphragmatic dysfunction produces symptoms that are observable in the region of the cervical base, in the floor of the mouth, and in the dura, as well as in the eyes. It is important to proceed in order; now we review in detail the connections of the vagus nerve, thereby clearly explaining the connections. The medial longitudinal fasciculus is an association of nerve fibers that connect the mesencephalon and most of the cranial nerves, including the trigeminal nerve, and the cranial nerves that innervate the eye (ie, II, III, IV, the first division of $\mathrm{V}$, and $\mathrm{VI}$ ), the tongue (the hypoglossal nerve, XII), and the cervical base (C1-C3). ${ }^{62-65}$ Therefore, the medial longitudinal fasciculus is an important connecting pathway, the margins of which go from the mesencephalondiencephalon to the lumbar spinal cord (L4) and further, at least according to some sources. ${ }^{62,66}$ This pathway is essential to understand the relationship between sight and posture.

The suboccipital muscles can be the cause of problems at the base of the neck, with consequent pain in the relevant dermatome at the level of the cranium. ${ }^{67}$ Moreover, these muscle regions have proprioceptive properties that are greater than those traced in larger muscles, such as gluteus maximus. ${ }^{68,69}$ In particular, with reference to the connections, the nerve of Arnold (greater occipital nerve - C2) enters the cranium (probably via the vagus or the hypoglossal nerve), where it innervates the inferior region of the tentorium cerebelli or tentorial diaphragm. ${ }^{61}$ In contrast, the superior area of the tentorium cerebelli is innervated by the recurrent nerve of Arnold, which is a stem of the first branch of the trigeminal nerve connected to the eye. ${ }^{61}$ Another possible symptom of diaphragmatic dysfunction is pain in the cranium, which can affect the ocular globe. The region innervated by the trigeminus, but generally any reciprocal tension membranes can synthesize vasoactive neuropeptides (calcitonin gene-related peptide, substance P, neurokinin A), which can initiate a series of painful reactions. ${ }^{58,70}$ According to some sources, the vagus and hypoglossus are among the nerves innervating the dura. ${ }^{61}$ Therefore, the vagus, which innervates the crural region of the diaphragm, can directly affect the system of reciprocal tension membranes, producing a range of relevant symptoms. According to recent research, stimulation of the trigeminal nerve can lead to cardiac arrhythmia and to a general decrease in arterial pressure with consequent bradycardia (Figure 3). ${ }^{61,71,72}$

The spinal trigeminal nucleus, which is connected to the vagus, is the destination of the trigeminal fibers from Gasser's ganglion. ${ }^{9}$ It should be noted that there is a close relationship between the diaphragm, the buccal diaphragm, and the 


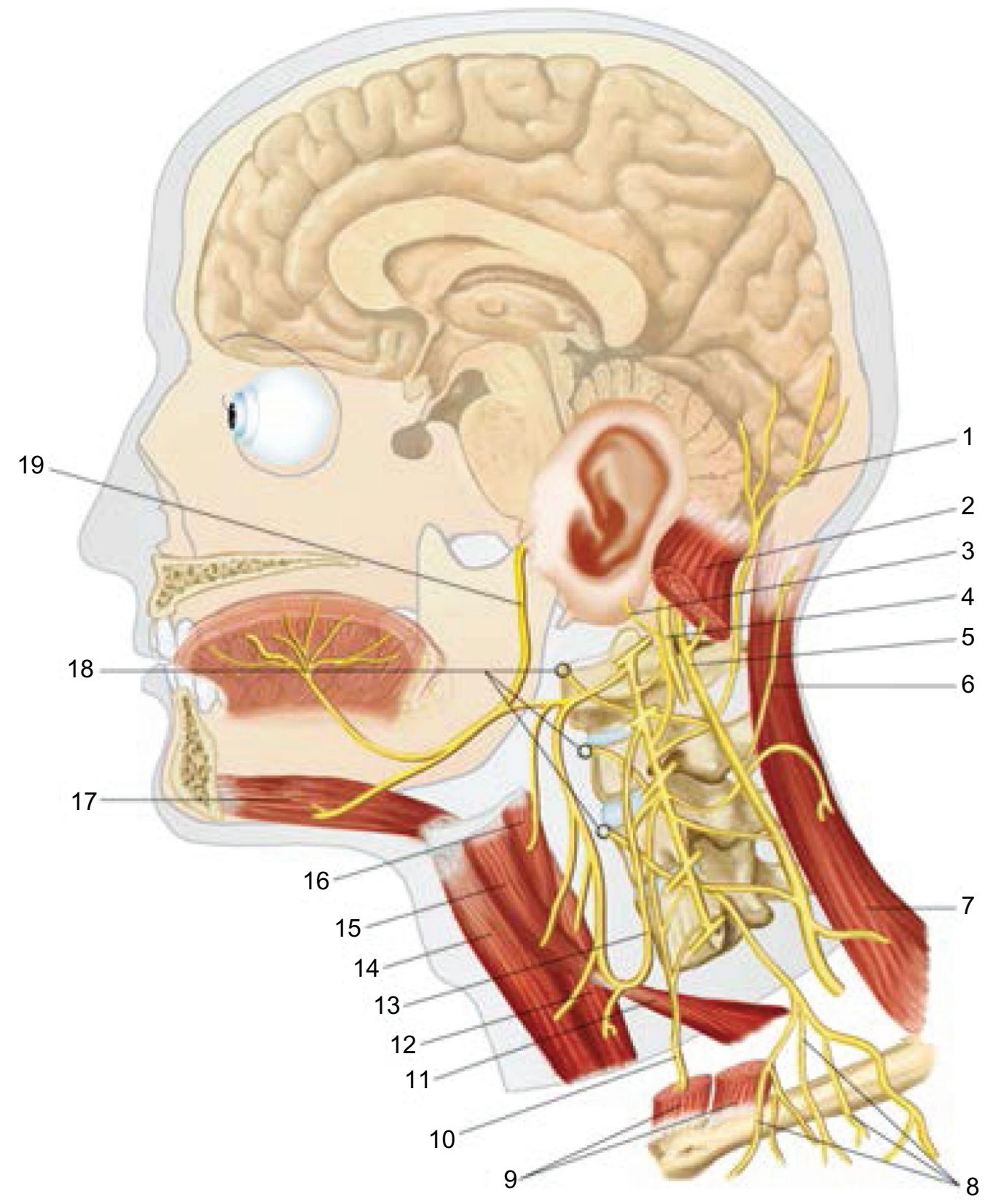

Figure 3 The cervico-cranial area: I: lesser occipital nerve or C2; 19: cranial nerve XII; 4: cranial nerve X; 5: cranial nerve Xl; 17: geniohyoid muscle; 10: phrenic nerve. AA VV, Anatomia dell'uomo, 4 ed, Edi.ermes, [Several authors, Human Anatomy, Fourth Edition, edition EdiErmes], Milano. www.eenet.it.

dura mater. ${ }^{34}$ This is housed in a division of the dura known as Meckel's cavity, the superior wall of which is strengthened by fibers deriving from the tentorium cerebelli, and is located near the petrous portion of the temporal bone. ${ }^{9}$ This nucleus is also connected to the cervical roots of $\mathrm{C} 2-\mathrm{C} 4 .{ }^{58,72,73}$ This means a more complex symptomatology concerning the whole face. According to a recent study, the rectus capitis posterior minor muscle (forming part of the deep fascia) is directly connected to the dura via a myotendinous junction, and consequently to the reciprocal tension membranes. ${ }^{74}$
Further, the nuchal ligament, innervated by $\mathrm{C} 2$, is also connected directly to the dura mater, ${ }^{75,76}$ and the trapezius muscle is part of the thoracolumbar fascia and possesses innervation which is close to the vagus nerve., ${ }^{9,77}$ With regard to symptoms, we can hypothesize that the phrenic nerve can affect the spinal trigeminal ganglia, which will stimulate the last two branches of the trigeminal nerve, reaching the periodontal ligaments through the alveolar nerves, and that the result will be dental pain. The same pathway may lead to pain in the temporomandibular joint and the ear through the 
ganglion of Gasser. Another link is through the transverse cervical nerve, which is a branch of the cervical plexus $(\mathrm{C} 2-\mathrm{C} 3)$, in direct contact with the mandibular branch of the trigeminal nerve. ${ }^{78}$

Carrying on our analysis of the vagal nerve, this nerve is firmly connected with the hypoglossal nerve, which is closely related to the trigeminal system. ${ }^{34,58,72}$ The hypoglossal nerve, which is a somatic efferent nerve, along its path is in contact with $\mathrm{C} 1-\mathrm{C} 2$ (namely, the suboccipital muscles), by their efferents. ${ }^{79}$ The floor of the mouth is linked to the trigeminal system by afferent fibers. ${ }^{80}$ The connection between the diaphragm and the floor of the mouth is easily recognized in the event of poor swallowing or sleep apnea, or again in the event of diaphragmatic dysfunction. ${ }^{81}$ The hypoglossal nerve receives a multitude of presynaptic impulses from the phrenic nerve and intercostal muscles. ${ }^{82}$ In regular respiration, the genioglossus and other muscles of the floor of the mouth, such as the hypoglossus, are electrically involved in coordination with the diaphragm, immediately before contraction of the diaphragm itself. ${ }^{81,83}$ Of all the muscles that dilate the pharynx, the genioglossus is the greatest, and is regarded as an accessory respiratory muscle. ${ }^{84}$ Involvement of this muscle prevents the muscles of the mouth from closing the superior respiratory tract during inhalation. ${ }^{81,83}$ The genioglossus moves during the respiratory cycle, ie, posteriorly during expiration and anteriorly during inspiration. ${ }^{85}$ This action guarantees correct ventilation.

The greater the inhalation phase in terms of rhythm, the greater the electrical response of these contractile areas in the mouth. ${ }^{82}$ This means that signals from the peripheral neurons combine with orders from the central nervous system. ${ }^{82,86} \mathrm{As}$ has been recently demonstrated, this carefully coordinated relationship can be disrupted by a range of respiratory problems, causing problems with chewing, swallowing, and breathing. ${ }^{87-89}$ Moreover, it should be noted that the pleura, innervated by the phrenic nerve, sends type $\mathrm{C}$ fibers to the tongue, indicating another close relationship between the diaphragm muscle and the buccal diaphragm..$^{90-92}$

Another neurologic connection with the diaphragm is represented by the orthosympathetic plexus of the greater splanchnic nerves, by the lesser and minimum splanchnic nerves. They pass the diaphragm in the crural region. ${ }^{24}$ According to recent anatomic dissection studies, the celiac ganglion originates in T4-T5-T9, whereas the superior mesenteric plexus derives from T10-T11-T12., ${ }^{8,10,11}$ Generally, they pass through the diaphragm via a common hiatus; occasionally, every splanchnic nerve runs through its own specific hiatus, always in the crural region. ${ }^{8,10,11}$ Finally, there is the inferior mesenteric plexus, which is composed of minimum splanchnic nerves, also known as the renal plexus or renal nerve. This plexus is related to L1-L2, ${ }^{8,10,11}$

The celiac ganglion, like other splanchnic branches, may vary in length, shape, size and location, but is not discussed in this paper. The splanchnic nerve system is essential in order to control the orthosympathetic visceral system. ${ }^{11}$ This suggests that, in the event of a diaphragmatic problem, whether a spasm or an atrophic lesion, the pathways of the orthosympathetic systems will be negatively affected in both the upward and downward directions. This means, on the one hand, that visceral activity will be affected, and on the other, that the metamers related to innervation of the three plexuses will suffer from pain in the vertebral facets and related tissues, and the muscle area of the affected metameric zone. ${ }^{11}$ Further, the visceral afferents are connected to Lissauer's tract (ie, the dorsolateral fasciculus or tract), which belongs to the trigeminal system. ${ }^{62,93-97}$ Therefore, a diaphragmatic disorder affecting the viscera innervated by the splanchnic system will result in pain even in distal areas. ${ }^{98,99}$

It is also important to mention the diaphragmatic ligaments. If these do not work properly, they may produce a nonphysiologic afferent environment, both for the diaphragm and for the structures connected to it. ${ }^{100}$ It is important to emphasize that when an organ such as the liver or the gallbladder does not function properly, the phrenic nerve will be affected. ${ }^{101,102}$ In fact, using the same example, the peritoneal surface related to the gallbladder and the hepatic attachment to the diaphragm are innervated by the phrenic nerve, with the consequent symptomatology described earlier in this paper. ${ }^{101,102}$ The same consideration is also identical in the event of hepatic dysfunction involving Glisson's capsule.

\section{Vascular and lymphatic connections}

Respiration is a constant and powerful modulator of cardiovascular control. ${ }^{103}$ It reduces negative intrathoracic pressure through inhalation (specifically, there is a suction with subsequent reduction of pressure on the right atrium) and, by means of a muscular contraction of the limbs, the venous drainage is enhanced. ${ }^{104}$ During inhalation, the inferior vena cava diameter decreases, ${ }^{104}$ and the efficiency of this process reaches its climax in slow and deep respiration. ${ }^{103}$ Research has shown that correct physiologic activity of the diaphragm will prevent any problem related to venous drainage. ${ }^{103}$ Therefore, if there are symptoms of venous stasis, examination of the diaphragm is recommended. There are cases of aortic compression or anomalies in the aortic bifurcation that may 
be caused by diaphragmatic disorders, although they are not too frequent. ${ }^{24}$ However, when diseases of the vascular tree have already been diagnosed, with a consequent increase in stiffness, appropriate physical therapy on the diaphragm will help the blood flow reach the peripheral areas. ${ }^{105}$

Lymphatic flow, helped by diaphragmatic contractile activity, leads from the peripheral diaphragm to the central tendon, with respect to the peritoneal surface. ${ }^{106}$ The lymph flowing from the diaphragm enters the parasternalmediastinal trunk and the thoracic duct, and finally enters the venous system. ${ }^{107}$ There is an efficient and rapid system of lymphatic drainage, especially in the peritoneal cavity. ${ }^{106}$ Lymphatic absorption firstly depends on the rhythmicity and stretching of the diaphragm, then on intraperitoneal pressure and the posture of the individual. ${ }^{106,108}$ These concepts are important because they exemplify how incorrect functionality of the diaphragm, for any reason, can negatively affect the lymphatic system. Further, it is important to remember the cisterna chyli, which is located under the diaphragmatic crural region and is the main destination point for the lymph. ${ }^{24}$

\section{Fascial connections}

Finally, it is important to consider the fascial and connective links between the diaphragm and the pelvic floor, and the rest of the body. First, the abdominal muscles are related to the costal, lumbar, and pubic iliac regions of the body, ie, rectus abdominis, the internal and external oblique muscles, pyramidalis, cremaster, transversus abdominis, great psoas, quadratus lumborum, sacrospinalis, and transversus spinalis (where the multifidus spinae is distinguishable)..$^{9,77}$ Moving now to the fascial links, it is important to consider that the fascia is rich in corpuscles (ie, Golgi's, Pacini's, and Ruffini's corpuscles), which have proprioceptive properties and provide significant peripheral information, as well as having a probable nociceptive function. ${ }^{77}$ Further, the fascial tissue possesses fibers capable of contracting, probably causing spasms, followed by dysfunction and pain. ${ }^{15,77,109,110}$

When there is a problem in the diaphragm or in any of the structures belonging to this fascia, there will be dysfunction. ${ }^{15,77,109}$ A physiologic alteration in any part of the body will affect everything that is covered by this connective sheet: the symptom will arise in the area concerned with the alteration or in a distal area, when this is not capable of adapting to the new stressor.

The fascia involving the diaphragm posteriorly, ie, at the retroperitoneal level, is separated in four parts. It joins the aortic system, inferior vena cava, liver, psoas muscles, quadratus lumborum, cardiac area, phrenic-esophageal ligaments and, finally, the kidneys. ${ }^{111,112}$ This system is known as the interfascial plane. ${ }^{111,112}$

Another important fascial system is the fascia transversalis, which is firmly connected to the transversus abdominis muscle and deserves our attention. ${ }^{17}$ This is a continuation of the endothoracic fascia and is related to the pleura, pericardium, and the diaphragm. ${ }^{16}$ It originates in the deep and median cervical fascia (ie, the neck, including the scalene muscles and the phrenic nerve), and goes to the occipital pharyngeal tubercle, where there is the dura mater, which is derived from the reciprocal tension membranes. ${ }^{26,113}$ Therefore, the deep cervical fascia reaches the pubis via the fascia transversalis. ${ }^{113}$ This fascia covers the epimysium of the transversus abdominis muscle, then arrives at the white line of the rectus abdominis, and reaches the inguinal and pubic regions. ${ }^{17}$ During its pathway, it particularly involves the external oblique and the inguinal canal. ${ }^{17}$ As far as the region of the inguinal canal is concerned, it has already been demonstrated that any dysfunction is determined by intra-abdominal pressure and not by the fascia previously described. ${ }^{114}$ However, when the muscles do not slide properly within the connective sheet, resulting in problems with the contractile pressures between the diaphragm and the subdiaphragmatic and perineal muscles, we can logically assume that the fascia plays an indirect role in pathologic physiology. It is important to remember that the transversus abdominis muscle, along with the respiratory diaphragm and the pelvic floor, plays a significant role in the stability of the sacroiliac joint. ${ }^{26,115,116}$ Another important fascial system is the thoracolumbar fascia, which develops posteriorly from the sacral region through the thoracic region, and finally to the cervical region. ${ }^{77}$ It involves muscles such as latissimus dorsi, trapezius, gluteus maximus, and the external oblique, as well as the ligaments that connect the ileum to the sacrum (the sacral bone belongs to the system of the pelvic floor). ${ }^{77,117}$ The gluteus maximus muscle runs in part anterior to the pelvic floor. ${ }^{117}$ The thoracolumbar fascia is essential for muscles that involve the column, ${ }^{15,17}$ and diaphragmatic dysfunction will negatively affect this tissue, leading to central and peripheral symptoms. For instance, in a proper physiologic context, the semispinalis muscles of the neck are mainly activated at the C2 level; however, when anomalous tensions are registered, the muscular stress will burden C5. ${ }^{118}$ Obviously, the phrenic nerve and any connections with this region may be negatively affected. Cervical pain can have diaphragmatic causes, and has repercussions for the neck through the thoracolumbar fascia. This is a bidirectional process, and this fascial bridge may explain pain related to the sacroiliac joint in the event of dysfunction between the diaphragm and the pelvic floor. 
The lateral raphe, ie, the fourth part of the fascial system that affects the diaphragm, originates at the twelfth rib and goes to the iliac crest, and is interesting with reference to the functionality of the respiratory diaphragm. ${ }^{119}$ In fact, the quadratus lumborum associated with the diaphragm is mainly connected to L2, and this contact is supported by the lateral raphe. ${ }^{24,119}$ The diaphragm acts mainly on L2 in order to stabilize the lumbar column and to control the resulting forces properly. ${ }^{120}$

These fascias are extremely important because they improve performance of the muscles. ${ }^{77,121,122}$ Indeed, the contractile forces are transmitted to all directions via the connective tissue, improving its tonus and, at the same time, sending information and moving all the body regions. ${ }^{110}$ If handling of these forces is restrained, postural and visceral equilibrium will become dysfunctional. ${ }^{35,114,123,124}$ We can assume that the phrenic nerve passes through the deep fascia and media, and be indirectly affected by the superficial fascia of the neck. ${ }^{34,125}$

\section{Conclusion}

The diaphragm muscle not only plays a role in respiration but also has many roles affecting the health of the body. It is important for posture, for proper organ function, and for the pelvis and floor of the mouth. It is important for the cervical spine and trigeminal system, as well as for the thoracic outlet. It is also of vital importance in the vascular and lymphatic systems. The diaphragm muscle should not be seen as a segment but as part of a body system. To arrive at correct therapeutic strategies, we must see the whole and all the links highlighted in this paper. In presenting this review, we hope to have made a small contribution towards perceiving the patient as a whole and to have spurred new thinking.

\section{Acknowledgment}

This paper is dedicated to the memory of John E Upledger and Philip E Greenman, both of whom were pioneers in the science of osteopathy.

\section{Disclosure}

The authors report no conflicts of interest in this work.

\section{References}

1. Downey R. Anatomy of the normal diaphragm. Thorac Surg Clin. 2011;21(2):273-279.

2. Anraku M, Shargall Y. Surgical conditions of the diaphragm: anatomy and physiology. Thorac Surg Clin. 2009;19(4):419-429.

3. Clugston RD, Greer JJ. Diaphragm development and congenital diaphragmatic hernia. Semin Pediatr Surg. 2007;16(2):94-100.
4. Arráez-Aybar LA, González-Gómez CC, Torres-García AJ, MorgagniLarrey. Parasternal diaphragmatic hernia in the adult. Rev Esp Enferm Dig. 2009;101(5):357-366.

5. Debergh I, Fierens K. Laparoscopic repair of a Bochdalek hernia with incarcerated bowel during pregnancy: report of a case. Surg Today. January 5, 2013. [Epub ahead of print.]

6. Dakwar E, Ahmadian A, Uribe JS. The anatomical relationship of the diaphragm to the thoracolumbar junction during the minimally invasive lateral extracoelomic (retropleural/retroperitoneal) approach. J Neurosurg Spine. 2012;16(4):359-364.

7. Shaw HM, Santer RM, Watson AH, Benjamin M. Adipose tissue at entheses: the innervation and cell composition of the retromalleolar fat pad associated with the rat Achilles tendon. J Anat. 2007;211(4): 436-443.

8. Mirjalili SA, Hale SJ, Buckenham T, Wilson B, Stringer MD. A reappraisal of adult thoracic surface anatomy. Clin Anat. 2012;25(7): 827-834.

9. Drake R, Vogl AW, Mitchell AWM. Gray's Anatomy for Students, 2nd ed. New York, NY: Elsevier-Churchill-Livingstone; 2009.

10. Gest TR, Hildebrandt S. The pattern of the thoracic splanchnic nerves as they pass through the diaphragm. Clin Anat. 2009;22(7): 809-814.

11. Loukas M, Klaassen Z, Merbs W, Tubbs RS, Gielecki J, Zurada A. A review of the thoracic splanchnic nerves and celiac ganglia. Clin Anat. 2010;23(5):512-522.

12. Ozel A, Toksoy G, Ozdogan O, Mahmutoglu AS, Karpat Z. Ultrasonographic diagnosis of median arcuate ligament syndrome: a report of two cases. Med Ultrason. 2012;14(2):154-157.

13. Cai W, Li HZ, Zhang X, et al. Medial arcuate ligament: a new anatomic landmark facilitates the location of the renal artery in retroperitoneal laparoscopic renal surgery. J Endourol. 2013;27(1):64-67.

14. Silverman PM, Cooper C, Zeman RK. Lateral arcuate ligaments of the diaphragm: anatomic variations at abdominal CT. Radiology. 1992;185(1):105-108.

15. Loukas M, Shoja MM, Thurston T, Jones VL, Linganna S, Tubbs RS. Anatomy and biomechanics of the vertebral aponeurosis part of the posterior layer of the thoracolumbar fascia. Surg Radiol Anat. 2008;30(2):125-129.

16. Skandalakis PN, Zoras O, Skandalakis JE, Mirilas P. Transversalis, endoabdominal, endothoracic fascia: who's who? Am Surg. 2006;72(1): $16-18$.

17. Peiper C, Junge K, Prescher A, Stumpf M, Schumpelick V. Abdominal musculature and the transversalis fascia: an anatomical viewpoint. Hernia. 2004;8(4):376-380.

18. Wang NS. Anatomy of the pleura. Clin Chest Med. 1998;19(2): 229-240.

19. Goenka AH, Shah SN, Remer EM. Imaging of the retroperitoneum. Radiol Clin North Am. 2012;50(2):333-355.

20. Finley DJ, Rusch VW. Anatomy of the pleura. Thorac Surg Clin. 2011;21(2):157-163.

21. Apaydin N, Uz A, Evirgen O, Loukas M, Tubbs RS, Elhan A. The phrenico-esophageal ligament: an anatomical study. Surg Radiol Anat. 2008;30(1):29-36.

22. van der Zypen E, Révész E. Investigation of development, structure and function of the phrenicocolic and duodenal suspensory ligaments. Acta Anat (Basel). 1984;119(3):142-148.

23. Kim SK, Cho CD, Wojtowycz AR. The ligament of Treitz (the suspensory ligament of the duodenum): anatomic and radiographic correlation. Abdom Imaging. 2008;33(4):395-397.

24. Restrepo CS, Eraso A, Ocazionez D, Lemos J, Martinez S, Lemos DF. The diaphragmatic crura and retrocrural space: normal imaging appearance, variants, and pathologic conditions. Radiographics. 2008;28(5): 1289-1305.

25. Roan E. The effect of Glisson's capsule on the superficial elasticity measurements of the liver. J Biomech Eng. 2010;132(10):104504.

26. Paoletti S. The Fasciae: Anatomy, Dysfunction and Treatment, 1st ed. Seattle, WA: Eastland Press; 2006. 
27. Pickering M, Jones JF. The diaphragm: two physiological muscles in one. J Anat. 2002;201(4):305-312.

28. Talasz H, Kremser C, Kofler M, Kalchschmid E, Lechleitner M, Rudisch A. Phase-locked parallel movement of diaphragm and pelvic floor during breathing and coughing - a dynamic MRI investigation in healthy females. Int Urogynecol J. 2011;22(1):61-68.

29. Mantilla CB, Sieck GC. Phrenic motor unit recruitment during ventilatory and non-ventilatory behaviors. Respir Physiol Neurobiol. 2011;179(1):57-63.

30. Boers J, Ford TW, Holstege G, Kirkwood PA. Functional heterogeneity among neurons in the nucleus retroambiguus with lumbosacral projections in female cats. J Neurophysiol. 2005;94(4):2617-2629.

31. Sadler TW. Langman's Medical Embryology, 12th ed. Philadelphia, PA: Wolters Kluwer Health Lippincott Williams \& Wilkins; 2012.

32. Nicaise C, Hala TJ, Frank DM, et al. Phrenic motor neuron degeneration compromises phrenic axonal circuitry and diaphragm activity in a unilateral cervical contusion model of spinal cord injury. Exp Neurol. 2012;235(2):539-552.

33. Jones SE, Saad M, Lewis DI, Subramanian HH, Dutschmann M. The nucleus retroambiguus as possible site for inspiratory rhythm generation caudal to obex. Respir Physiol Neurobiol. 2012;180(2-3):305-310.

34. Banneheka S. Morphological study of the ansa cervicalis and the phrenic nerve. Anat Sci Int. 2008;83(1):31-44.

35. Kolar P, Sulc J, Kyncl M, et al. Stabilizing function of the diaphragm: dynamic MRI and synchronized spirometric assessment. $J$ Appl Physiol. 2010;109(4):1064-1071.

36. Kwan CS, Worrilow CC, Kovelman I, Kuklinski JM. Using suboccipital release to control singultus: a unique, safe, and effective treatment. $\mathrm{Am}$ J Emerg Med. 2012;30(3):514. e5-e7.

37. Giles PD, Hensel KL, Pacchia CF, Smith ML. Suboccipital decompression enhances heart rate variability indices of cardiac control in healthy subjects. J Altern Complement Med. 2013;19(2): 92-96.

38. An X, Yue B, Lee JH, Lee MS, Lin C, Han SH. Intramuscular distribution of the phrenic nerve in human diaphragm as shown by Sihler staining. Muscle Nerve. 2012;45(4):522-526.

39. Correa D, Segal SS. Neurovascular proximity in the diaphragm muscle of adult mice. Microcirculation. 2012;19(4):306-315.

40. Townend RE, McConnell P. The right inferior phrenic artery: path of its ascending branch at the vena caval foramen. Clin Anat. 2012;25(5): 656-658

41. Young RL, Page AJ, Cooper NJ, Frisby CL, Blackshaw LA. Sensory and motor innervation of the crural diaphragm by the vagus nerves Gastroenterology. 2010;138(3):1091-1101. e1-e5.

42. Niedringhaus M, Jackson PG, Evans SR, Verbalis JG, Gillis RA, Sahibzada N. Dorsal motor nucleus of the vagus: a site for evoking simultaneous changes in crural diaphragm activity, lower esophageal sphincter pressure, and fundus tone. Am J Physiol Regul Integr Comp Physiol. 2008;294(1):R121-R131.

43. Zhao T, Li Y, Dai X, et al. Effects of retrograde gene transfer of brainderived neurotrophic factor in the rostral spinal cord of a compression model in rat. Mol Biol Rep. 2012;39(8):8045-8051.

44. Yampolsky C, Hem S, Bendersky D. Dorsal column stimulator applications. Surg Neurol Int. 2012;3 Supp1 4:S275-S289.

45. Russell FD, Koishi K, Jiang Y, McLennan IS. Anterograde axonal transport of glial cell line-derived neurotrophic factor and its receptors in rat hypoglossal nerve. Neuroscience. 2000;97(3):575-580.

46. Helke CJ, Adryan KM, Fedorowicz J, et al. Axonal transport of neurotrophins by visceral afferent and efferent neurons of the vagus nerve of the rat. J Comp Neurol. 1998;393(1):102-117.

47. Mantilla CB, Sieck GC. Trophic factor expression in phrenic motor neurons. Respir Physiol Neurobiol. 2008;164(1-2):252-262.

48. Pedersen BK, Febbraio MA. Muscles, exercise and obesity: skeletal muscle as a secretory organ. Nat Rev Endocrinol. 2012;8(8): 457-465.

49. Barraclough A, Triplett J, Tuch P. Brachial neuritis with phrenic nerve involvement. J Clin Neurosci. 2012;19(9):1301-1302.
50. Prakash, Prabhu LV, Madhyastha S, Singh G. A variation of the phrenic nerve: case report and review. Singapore Med J. 2007;48(12): $1156-1157$.

51. Zhang Z, Dellon AL. Facial pain and headache associated with brachial plexus compression in the thoracic inlet. Microsurgery. 2008;28(5): $347-350$.

52. Laulan J, Fouquet B, Rodaix C, Jauffret P, Roquelaure Y, Descatha A. Thoracic outlet syndrome: definition, aetiological factors, diagnosis, management and occupational impact. J Occup Rehabil. 2011;21(3): 366-373.

53. Ferrante MA. The thoracic outlet syndromes. Muscle Nerve. 2012; 45(6):780-795.

54. Franko OI, Khalpey Z, Gates J. Brachial plexus trauma: the morbidity of hemidiaphragmatic paralysis. Emerg Med J. 2008;25(9):614-615.

55. Bałkowiec A, Szulczyk P. Properties of postganglionic sympathetic neurons with axons in phrenic nerve. Respir Physiol. 1992;88(3) 323-331.

56. Nozdrachev AD, Fateev MM, Jiménez B, Morales MA. Circuits and projections of cat stellate ganglion. Arch Med Res. 2003;34(2): 106-115.

57. Lachman N, Syed FF, Habib A, et al. Correlative anatomy for the electrophysiologist, Part II: cardiac ganglia, phrenic nerve, coronary venous system. J Cardiovasc Electrophysiol. 2011;22(1):104-110.

58. Messlinger K, Fischer MJ, Lennerz JK. Neuropeptide effects in the trigeminal system: pathophysiology and clinical relevance in migraine. Keio J Med. 2011;60(3):82-89.

59. Eherer AJ, Netolitzky F, Högenauer C, et al. Positive effect of abdominal breathing exercise on gastroesophageal reflux disease: a randomized, controlled study. Am J Gastroenterol. 2012;107(3):372-378.

60. da Silva RC, de Sá CC, Pascual-Vaca AO, et al. Increase of lower esophageal sphincter pressure after osteopathic intervention on the diaphragm in patients with gastroesophageal reflux. Dis Esophagus. June 7, 2012. [Epub ahead of print.]

61. Kemp WJ 3rd, Tubbs RS, Cohen-Gadol AA. The innervation of the cranial dura mater: neurosurgical case correlates and a review of the literature. World Neurosurg. 2012;78(5):505-510.

62. Haines DE. Neuroanatomy. An Atlas of Structures, Sections, and System, 6th ed. Lippincott Williams \& Wilkins; 2044.

63. Bae YJ, Kim JH, Choi BS, Jung C, Kim E. Brainstem pathways for horizontal eye movement: pathologic correlation with MR imaging. Radiographics. 2013;33(1):47-59.

64. Sakaie K, Takahashi M, Dimitrov I, et al. Diffusion tensor imaging the medial longitudinal fasciculus in INO: opportunities and challenges. Ann N Y Acad Sci. 2011;1233:307-312.

65. Zwergal A, Strupp M, Brandt T, Büttner-Ennever JA. Parallel ascending vestibular pathways: anatomical localization and functional specialization. Ann N Y Acad Sci. 2009;1164:51-59.

66. Kushiro K, Bai R, Kitajima N, Sugita-Kitajima A, Uchino Y. Properties and axonal trajectories of posterior semicircular canal nerve-activated vestibulospinal neurons. Exp Brain Res. 2008;191(3): $257-264$.

67. Grgić V. Cervicogenic headache: etiopathogenesis, characteristics, diagnosis, differential diagnosis and therapy. Lijec Vjesn. 2007;129(6-7): 230-236. Croatian.

68. Kulkarni V, Chandy MJ, Babu KS. Quantitative study of muscle spindles in suboccipital muscles of human foetuses. Neurol India. 2001;49(4):355-359.

69. Proske U, Gandevia SC. The proprioceptive senses: their roles in signaling body shape, body position and movement, and muscle force. Physiol Rev. 2012;92(4):1651-1697.

70. Messlinger K, Lennerz JK, Eberhardt M, Fischer MJ. CGRP and NO in the trigeminal system: mechanisms and role in headache generation. Headache. 2012;52(9):1411-1427.

71. Meng Q, Zhang W, Yang Y, Zhou M, Li X. Cardiovascular responses during percutaneous radiofrequency thermocoagulation therapy in primary trigeminal neuralgia. $J$ Neurosurg Anesthesiol. 2008;20(2): 131-135. 
72. Adeeb N, Mortazavi MM, Tubbs RS, Cohen-Gadol AA. The cranial dura mater: a review of its history, embryology, and anatomy. Childs Nerv Syst. 2012;28(6):827-837.

73. Upadhyay J, Knudsen J, Anderson J, Becerra L, Borsook D. Noninvasive mapping of human trigeminal brainstem pathways. Magn Reson Med. 2008;60(5):1037-1046.

74. Kahkeshani K, Ward PJ. Connection between the spinal dura mater and suboccipital musculature: evidence for the myodural bridge and a route for its dissection - a review. Clin Anat. 2012;25(4):415-422.

75. Dean NA, Mitchell BS. Anatomic relation between the nuchal ligament (ligamentum nuchae) and the spinal dura mater in the craniocervical region. Clin Anat. 2002;15(3):182-185.

76. Tubbs RS, Salter EG, Wellons JC, Blount JP, Oakes WJ. Landmarks for the identification of the cutaneous nerves of the occiput and nuchal regions. Clin Anat. 2007;20(3):235-238.

77. Willard FH, Vleeming A, Schuenke MD, Danneels L, Schleip R. The thoracolumbar fascia: anatomy, function and clinical considerations. $J$ Anat. 2012;221(6):507-536.

78. Lin K, Uzbelger Feldman D, Barbe MF. Transverse cervical nerve: implications for dental anesthesia. Clin Anat. January 29, 2013. [Epub ahead of print.]

79. Banneheka S. Anatomy of the ansa cervicalis: nerve fiber analysis. Anat Sci Int. 2008;83(2):61-67.

80. Bademci G, Yaşargil MG. Microsurgical anatomy of the hypoglossal nerve. J Clin Neurosci. 2006;13(8):841-847.

81. Borel JC, Melo-Silva CA, Gakwaya S, Sériès F. Influence of $\mathrm{CO}_{2}$ on upper airway muscles and chest wall/diaphragm corticomotor responses assessed by transcranial magnetic stimulation in awake healthy subjects. J Appl Physiol. 2012;112(5):798-805.

82. Rice A, Fuglevand AJ, Laine CM, Fregosi RF. Synchronization of presynaptic input to motor units of tongue, inspiratory intercostal, and diaphragm muscles. J Neurophysiol. 2011;105(5):2330-2336.

83. Wang W, Similowski T, Sériès F. Interaction between genioglossus and diaphragm responses to transcranial magnetic stimulation in awake humans. Exp Physiol. 2007;92(4):739-747.

84. Aleksandrova NP. Respiratory function of pharyngeal muscles. Usp Fiziol Nauk. 2006;37(3):11-24. Russian.

85. Cheng S, Butler JE, Gandevia SC, Bilston LE. Movement of the tongue during normal breathing in awake healthy humans. J Physiol. 2008; 586 Pt 17:4283-4294.

86. Uysal H, Kızılay F, Unal A, Güngör HA, Ertekin C. The interaction between breathing and swallowing in healthy individuals. J Electromyogr Kinesiol. 2013;23(3):659-663.

87. Cifra A, Nani F, Nistri A. Respiratory motoneurons and pathological conditions: lessons from hypoglossal motoneurons challenged by excitotoxic or oxidative stress. Respir Physiol Neurobiol. 2011;179(1): 89-96.

88. Grace KP, Hughes SW, Horner RL. Identification of the mechanism mediating genioglossus muscle suppression in REM sleep. Am J Respir Crit Care Med. 2013;187(3):311-319.

89. Luo YM, Tang J, Jolley C, et al. Distinguishing obstructive from central sleep apnea events: diaphragm electromyogram and esophageal pressure compared. Chest. 2009;135(5): 1133-1141.

90. Lee KZ, Fuller DD, Lu IJ, Lin JT, Hwang JC. Neural drive to tongue protrudor and retractor muscles following pulmonary $\mathrm{C}$-fiber activation. J Appl Physiol. 2007;102(1):434-444.

91. Lee KZ, Fuller DD, Hwang JC. Pulmonary C-fiber activation attenuates respiratory-related tongue movements. J Appl Physiol. 2012;113(9): 1369-1376

92. Jiang S, Xu WD, Shen YD, Xu JG, Gu YD. An anatomical study of the full-length phrenic nerve and its blood supply: clinical implications for endoscopic dissection. Anat Sci Int. 2011;86(4):225-231.

93. Lidierth M. Long-range projections of Adelta primary afferents in the Lissauer tract of the rat. Neurosci Lett. 2007;425(2):126-130.

94. Wild JM, Zeigler HP. Central projections and somatotopic organisation of trigeminal primary afferents in pigeon (Columba livia). J Comp Neurol. 1996;368(1):136-152.
95. Cervero F, Connell LA. Distribution of somatic and visceral primary afferent fibres within the thoracic spinal cord of the cat. J Comp Neurol. 1984;230(1): 88-98.

96. Lidierth M, Wall PD. Dorsal horn cells connected to the Lissauer tract and their relation to the dorsal root potential in the rat. JNeurophysiol. 1998;80(2):667-679.

97. Wall PD, Lidierth M, Hillman P. Brief and prolonged effects of Lissauer tract stimulation on dorsal horn cells. Pain. 1999;83(3): 579-589.

98. Nakano M, Kishida R, Funakoshi K, et al. Central projections of thoracic splanchnic and somatic nerves and the location of sympathetic preganglionic neurons in Xenopus laevis. J Comp Neurol. 2003;456(4): 321-337.

99. Mørch CD, Hu JW, Arendt-Nielsen L, Sessle BJ. Convergence of cutaneous, musculoskeletal, dural and visceral afferents onto nociceptive neurons in the first cervical dorsal horn. Eur J Neurosci. 2007;26(1): $142-154$.

100. Levinthal DJ, Bielefeldt K. Pain without nociception? Eur J Gastroenterol Hepatol. 2012;24(3):336-339.

101. Barrall JP, Mercier P. Visceral Manipulation. Revised Edition, Volume I. Seattle, WA: Eastland Press; 2006.

102. Barrall JP, Mercier P. Visceral Manipulation. Revised Edition, Volume II. Seattle, WA: Eastland Press; 2007.

103. Byeon $\mathrm{K}$, Choi JO, Yang JH, et al. The response of the vena cava to abdominal breathing. J Altern Complement Med. 2012;18(2): $153-157$.

104. Kimura BJ, Dalugdugan R, Gilcrease GW 3rd, Phan JN, Showalter BK, Wolfson T. The effect of breathing manner on inferior vena caval diameter. Eur J Echocardiogr. 2011;12(2):120-123.

105. Chiappa GR, Roseguini BT, Vieira PJ, et al. Inspiratory muscle training improves blood flow to resting and exercising limbs in patients with chronic heart failure. J Am Coll Cardiol. 2008;51(17):1663-1671.

106. Abu-Hijleh MF, Habbal OA, Moqattash ST. The role of the diaphragm in lymphatic absorption from the peritoneal cavity. J Anat. 1995;186 Pt 3:453-467.

107. Negrini D, Moriondo A. Lymphatic anatomy and biomechanics. J Physiol. 2011;589 Pt 12:2927-2934.

108. Moriondo A, Bianchin F, Marcozzi C, Negrini D. Kinetics of fluid flux in the rat diaphragmatic submesothelial lymphatic lacunae. Am J Physiol Heart Circ Physiol. 2008;295(3):H1182-H1190.

109. Stecco C, Stern R, Porzionato A, et al. Hyaluronan within fascia in the etiology of myofascial pain. Surg Radiol Anat. 2011;33(10): 891-896.

110. Tozzi P. Selected fascial aspects of osteopathic practice. J Bodyw Mov Ther. 2012;16(4):503-519.

111. Lee SL, Ku YM, Rha SE, Comprehensive reviews of the interfascial plane of the retroperitoneum: normal anatomy and pathologic entities. Emerg Radiol. 2010;17(1):3-11.

112. Tirkes T, Sandrasegaran K, Patel AA, et al. Peritoneal and retroperitoneal anatomy and its relevance for cross-sectional imaging. Radiographics. 2012;32(2):437-451.

113. Mihalache G, Indrei A, Tăranu T. The anterolateral structures of the neck and trunk. Rev Med Chir Soc Med Nat Iasi. 1996;100(1-2):69-74.

114. Hung HC, Hsiao SM, Chih SY, Lin HH, Tsauo JY. An alternative intervention for urinary incontinence: retraining diaphragmatic, deep abdominal and pelvic floor muscle coordinated function. Man Ther. 2010;15(3):273-279.

115. O'Sullivan PB, Beales DJ. Changes in pelvic floor and diaphragm kinematics and respiratory patterns in subjects with sacroiliac joint pain following a motor learning intervention: a case series. Man Ther. 2007;12(3):209-118.

116. Bø K, Sherburn M. Evaluation of female pelvic-floor muscle function and strength. Phys Ther. 2005;85(3):269-282.

117. Soljanik I, Janssen U, May F, et al. Functional interactions between the fossa ischioanalis, levator ani and gluteus maximus muscles of the female pelvic floor: a prospective study in nulliparous women. Arch Gynecol Obstet. 2012;286(4):931-938. 
118. Schomacher J, Dideriksen JL, Farina D, Falla D. Recruitment of motor units in two fascicles of the semispinalis cervicis muscle. J Neurophysiol. 2012;107(11):3078-3085.

119. Schuenke MD, Vleeming A, Van Hoof T, Willard FH. A description of the lumbar interfascial triangle and its relation with the lateral raphe: anatomical constituents of load transfer through the lateral margin of the thoracolumbar fascia. J Anat. 2012;221(6):568-576.

120. Hodges PW, Eriksson AE, Shirley D, Gandevia SC. Intra-abdominal pressure increases stiffness of the lumbar spine. J Biomech. 2005; 38(9):1873-1880.

121. Stecco C, Macchi V, Porzionato A, Duparc F, De Caro R. The fascia: the forgotten structure. Ital J Anat Embryol. 2011;116(3):127-138.
122. Day JA, Copetti L, Rucli G. From clinical experience to a model for the human fascial system. J Bodyw Mov Ther. 2012;16(3): 372-380.

123. $\mathrm{Hu} \mathrm{H}$, Meijer OG, Hodges PW, et al. Control of the lateral abdominal muscles during walking. Hum Mov Sci. 2012;31(4):880-896.

124. Kolar P, Sulc J, Kyncl M, et al. Postural function of the diaphragm in persons with and without chronic low back pain. J Orthop Sports Phys Ther. 2012;42(4):352-362.

125. Warshafsky D, Goldenberg D, Kanekar SG. Imaging anatomy of deep neck spaces. Otolaryngol Clin North Am. 2012;45(6):1203-1221.

\section{Publish your work in this journal}

The Journal of Multidisciplinary Healthcare is an international, peerreviewed open-access journal that aims to represent and publish research in healthcare areas delivered by practitioners of different disciplines. This includes studies and reviews conducted by multidisciplinary teams as well as research which evaluates the results or conduct of such teams or

\section{Dovepress}

healthcare processes in general. The journal covers a wide range of areas and welcomes submission from practitioners at all levels, from all over the world. The manuscript management system is completely online and includes a very quick and fair peer-review system. Visit http://www.dovepress.com/testimonials.php to read real quotes from published authors.

Submit your manuscript here: http://www.dovepress.com/journal-of-multidisciplinary-healthcare-journal 